\title{
Does the Fed Act Gradually? A VAR Analysis *
}

\author{
Brian Sack \\ Board of Governors of the Federal Reserve System
}

April 1998

\begin{abstract}
The tendency for changes in the federal funds rate to be implemented gradually has been considered evidence of an interest-rate smoothing objective for the Federal Reserve. This paper investigates whether gradual movements in the federal funds rate can be explained by the dynamic structure of the economy and the uncertainty that the Fed faces regarding this structure, without recourse to including an ad-hoc interest rate smoothing argument in the objective function of the Fed. The analysis calculates the optimal funds rate policy given the structural form of the economy estimated in a VAR. In the absence of parameter uncertainty, the calculated policy responds more aggressively to changes in the economy than the observed policy, resulting in a substantially higher volatility of the funds rate than observed. Parameter uncertainty, however, limits the willingness of the Fed to deviate from the policy rule that has been previously implemented. Because the Fed has historically smoothed interest rates, the calculated policy under parameter uncertainty can account for a considerable portion of the gradualism observed in funds rate movements.
\end{abstract}

*I am indebted to Olivier Blanchard and Jeremy Stein for their valuable suggestions and comments. I also wish to thank Anil Kashyap, Athanasios Orphanides, Vincent Reinhart, and Roberto Rigobon for helpful discussions. The opinions expressed are those of the author and do not necessarily reflect the views of the Board of Governors of the Federal Reserve System or other members of its staff. 


\section{Introduction}

Once the Fed starts raising rates, multiple rate hikes are par for the course. ${ }^{1}$

There is a widespread belief among investors as well as economists that the Federal Reserve conducts monetary policy in a gradual manner. This belief may stem from the fact that the Fed has historically implemented movements in the federal funds rate using sequences of small interest rate changes. This behavior is demonstrated in Figure 1, which presents the intended federal funds rate over the period January 1984 to September $1997{ }^{2}$ As evident in the figure, the federal funds rate tends to move in a particular direction over sustained periods of time. In addition, changes in the federal funds rate appear to be implemented tentatively, requiring a large number of steps to complete a directional movement.

The gradual behavior of the federal funds rate can be demonstrated with some simple statistics. There is a strong tendency for changes in the funds rate to be followed by additional changes in the same direction. In this sample, 85.5 percent of the target changes are continuations, or have the same sign as the previous change. In addition, continuations tend to occur in rapid succession. The average length of time between continuations is 33 days, much shorter than the 103 days that elapse on average when the next change is a reversal. ${ }^{3}$ The frequency and timing of consecutive interest rate changes suggest that continuations often constitute steps within a single policy movement, while reversals may instead describe the beginning of a new policy action.

This deliberate pace of movements in the federal funds rate has been considered evidence of an interest-rate smoothing incentive for the Federal Reserve. Under this interpretation, the Federal Reserve is reluctant to change the funds rate aggressively, choosing instead to move the interest rate tentatively towards its new level. To describe this behavior, which

\footnotetext{
${ }^{1}$ This comment was quoted in the New York Times following an increase in the federal funds rate by the Federal Reserve on March 25, 1997.

${ }^{2}$ The target series is that which is reported in Rudebusch(1995) through 1992:9. The target series has been extended through 1997:9 based on press releases by the FOMC announcing policy actions.

${ }^{3}$ Rudebusch(1995) presents more formal evidence of this behavior in a paper about the implications of gradual funds rate movements for the term structure of interest rates. He estimates non-parametric hazard rates showing that in the first several weeks following a target change, a continuation is much more likely than a reversal, while once four weeks have elapsed since the last target change, the target behaves much more like a random walk.
} 


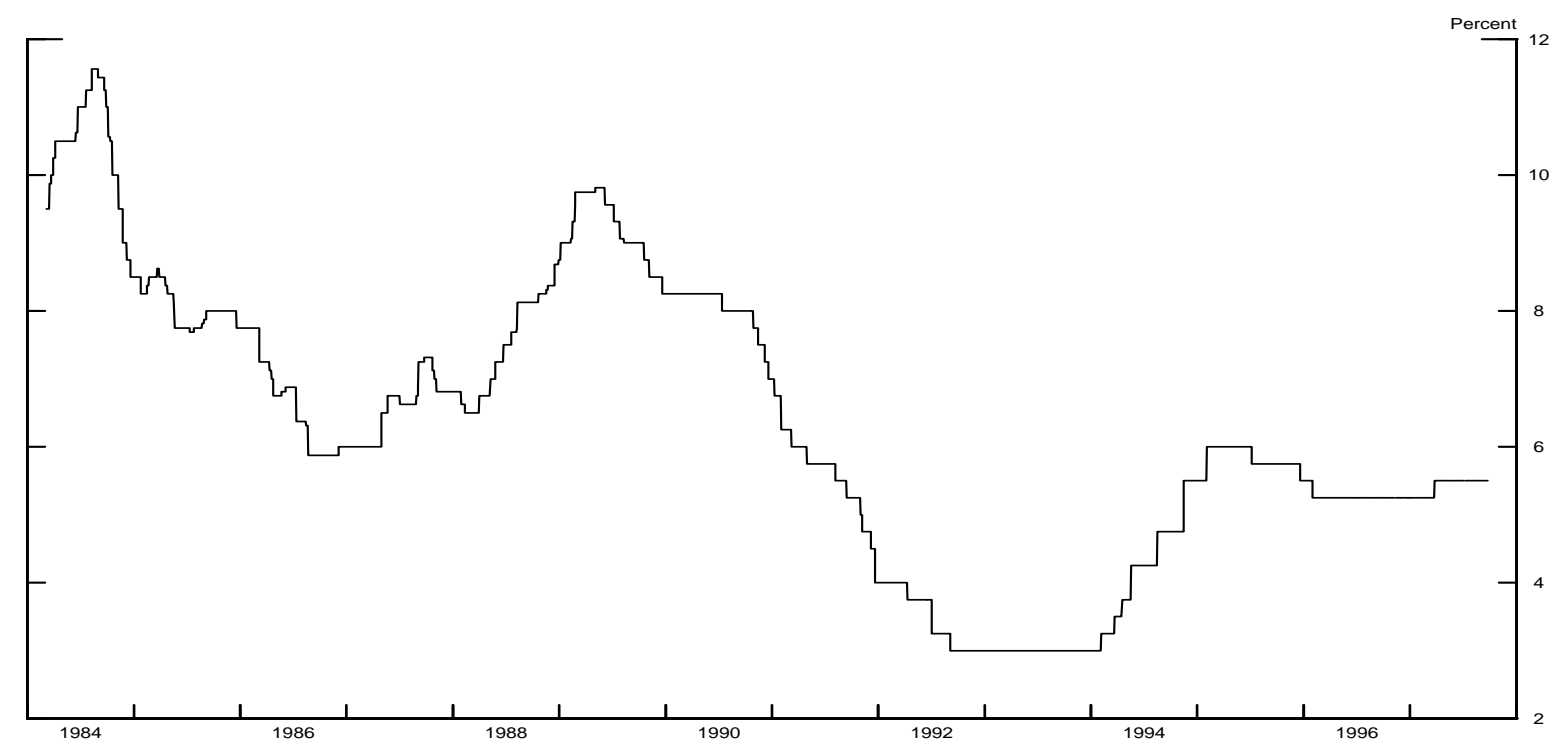

Figure 1: Intended Federal Funds Rate

has been referred to as gradualism, many empirical studies of monetary policy incorporate an explicit interest-rate smoothing incentive in the objective function of the Fed. However, introducing this argument has little justification beyond matching the data. Furthermore, the above statistics provide evidence of gradualism only if the Fed would otherwise choose a random-walk policy in the absence of an interest-rate smoothing objective. Therefore, while establishing that the funds rate is not a random walk, these statistics do not necessarily provide evidence of gradualism in monetary policy.

This paper investigates whether gradual movements in the federal funds rate can be explained by the dynamic structure of the economy and the uncertainty that the Fed faces regarding this structure, assuming that the only objective of the Fed is macroeconomic stability. In formulating its current and future policy choices, the Fed must consider the current state of the economy and the dynamic behavior of the non-policy variables in the economy. Because these variables exhibit strong serial correlation and respond to monetary policy with a substantial lag, inertial movements in the funds rate may be expected even in the absence of an interest-rate smoothing objective. Taking this into consideration, gradualism is defined as the tendency to limit changes in the federal funds rate to a greater degree than can be 
accounted for by the dynamic structure of the economy. ${ }^{4}$ Gradual monetary policy would smooth the response of the funds rate to a change in the state of the economy, resulting in higher serial correlation of funds rate changes than expected from the dynamic behavior of the economy.

Section 2 of the paper provides evidence of gradualism under this more stringent definition. A vector autoregression (VAR) is estimated, and the structural form of the economy is partially identified using a minimum number of restrictions. Given this dynamic structure, the analysis calculates the funds rate policy that maximizes an objective function involving the discounted sum of deviations of production growth, unemployment, and inflation from their respective targets. The analysis assumes that all of the uncertainty in the economy enters through additive disturbances. As a result, the calculated policy is not affected by the degree of uncertainty and only reflects the dynamic structure that has been estimated. The calculated policy depends on the lagged funds rate to the extent warranted by the intertemporal structure of the economy. This policy can therefore be compared to the actual behavior of the funds rate to determine whether actual funds rate movements are excessively gradual.

The results indicate that the estimated dynamic structure of the economy can account for the observed persistence of the directional movements in the funds rate. The optimal policy displays a tendency to move in a particular direction over sustained periods of time, as found in the data. Still, the optimal policy responds more aggressively to changes in the state of the economy than the observed policy. As a result, the funds rate path under the optimal policy is more volatile than the actual funds rate. Moreover, the observed policy tends to lag behind the optimal policy, limiting any changes in the funds rate and gradually moving towards the optimal policy over a period of 6 months. The actual policy is therefore described by an excessive amount of interest-rate smoothing that cannot be explained strictly by the dynamic behavior of the variables to which the Fed is responding.

The interest-rate smoothing that is observed may reflect the cautious reaction of the Fed to uncertainty over the dynamic structure of the economy. If the effect of monetary policy on the economy is uncertain, strong funds rate movements would induce a high level of variance in the targeted variables. It may instead be optimal to adjust the funds rate deliberately to

\footnotetext{
${ }^{4}$ Defined as such, gradualism corresponds to the concept of interest-rate smoothing. Other authors have used the term gradualism to describe a reluctance to move the funds rate from a level other than the lagged funds rate, such as the equilibrium real rate plus inflation.
} 
limit any undesired impact on the economy.

In section 3 of the paper, the calculated funds rate policy accounts for the fact that the parameters of the structural form of the economy are estimated imprecisely in the VAR. The analysis demonstrates that the variance of the targeted variables arising from parameter uncertainty is minimized at the level of the funds rate predicted by the estimated reaction function of the Fed. Because it has observed the effect of the policy rule that has been previously implemented, the Fed has the most precise estimates about the response of the economy when it chooses the funds rate according to that rule. As a result, parameter uncertainty of this form constrains the current policymaker not to act too much at variance from the policy rule that has been previously implemented. This reluctance to change the policy rule dampens the aggressive funds rate changes under the optimal policy since the Fed has historically smoothed interest rates. The analysis under parameter uncertainty can therefore account for a considerable portion of the gradual funds rate movements observed.

By controlling for the effects of dynamic structure and parameter uncertainty, the exercise provides a measure of the degree of interest-rate smoothing that is inconsistent with the objective function assumed. In general, there remains an element of interest-rate smoothing in the data, but this tendency may be less extensive than previously believed. The calculated policy continues to react more strongly to changes in the economy, while the observed policy smoothes the response of the funds rate over a period of several months. However, the volatility of the funds rate under the optimal policy is only slightly higher than the observed volatility. In addition, deviations between the actual and optimal funds rate are typically eliminated within 3 months.

\section{Gradualism under Additive Uncertainty}

The analysis in this section investigates whether gradual movements in the federal funds rate stem from the dynamic structure of the economy. The dynamic behavior of the non-policy variables is assumed to be given by the point estimates of the structural form identified from a VAR plus an additive disturbance that is independently distributed. Using this estimated structure, the solution to a dynamic programming problem yields the interest rate policy that would be expected if the Fed were concerned only with the goal of macroeconomic stability. 
The funds rate policy that results from this optimization problem is a function of all current and lagged variables in the economy in a manner that takes into consideration the dynamic behavior of these variables. In particular, the optimal funds rate will depend on lagged values of the funds rate to an extent determined by the intertemporal structure of the economy. The behavior of this optimal policy is then compared to the actual policy behavior estimated in the VAR to investigate whether actual funds rate movements are excessively gradual.

The optimal policy is derived assuming that the structure of the economy is invariant to the policy chosen by the Fed and is therefore subject to the Lucas(1976) critique. While the Lucas critique applies to all optimal policy analysis, the criticism may be more persuasive in the context of a VAR. The VAR is a reduced form in which the parameters reflect structural relationships as well as the formation of expectations. Because expectations in particular will be sensitive to policy rules, the parameters of the VAR will depend on the policy that is implemented. ${ }^{5}$

The VAR estimates describe the responsiveness of the economy to monetary policy, given the expectation that the Fed is following the observed policy rule. The calculated policy depicts the funds rate that the Fed would implement, conditional on the expectation that it will act gradually. Because of this, the results in the case of additive uncertainty are more susceptible to the Lucas critique, as the calculated policy deviates substantially from the observed policy. However, the calculated policy under parameter uncertainty involves only limited deviations from the observed policy, thereby reducing the significance of the Lucas critique. ${ }^{6}$

\footnotetext{
${ }^{5}$ Recent attempts to perform optimal policy analysis using structural models of the economy include Fuhrer(1997), Fuhrer and Moore(1995), and Rotemberg and Woodford(1997). The relative merits of the VAR and structural approaches is discussed by Sims(1996). These papers have not considered the effect of parameter uncertainty on the optimal policy.

${ }^{6}$ Other authors have analyzed much larger deviations in policy in the context of a VAR. For example, Sims and Zha(1996) completely eliminate the endogenous response of the funds rate to a shock in the VAR.
} 


\subsection{Calculating the Optimal Policy}

The VAR that is estimated assumes that the economy is described by the following linear structural model:

$$
\begin{aligned}
\mathbf{Z}_{t} & =\sum_{i=0}^{q} \mathbf{A}_{i} \mathbf{Z}_{t-i}+\sum_{i=0}^{q} \mathbf{b}_{i} i_{t-i}+\mathbf{v}_{t}^{Z} \\
i_{t} & =\sum_{i=0}^{q} \mathbf{c}_{i}^{\prime} \mathbf{Z}_{t-i}+\sum_{i=1}^{q} d_{i} i_{t-i}+v_{t}^{i}
\end{aligned}
$$

where $\mathbf{Z}_{t}$ is an $n \times 1$ vector of non-policy variables, $i_{t}$ is the policy variable, $q$ is the number of lags in the VAR, and boldface denotes matrices or vectors. This is a system of simultaneous equations in which each variable is allowed to depend on the current and lagged values of all other variables in the system. The $\mathbf{v}_{t}^{Z}$ and $v_{t}^{i}$ terms are the uncorrelated structural disturbances to the system. The vector of non-policy variables in the VAR is given by $\mathbf{Z}_{t}=\left[\begin{array}{llll}y_{t} & u_{t} & \pi_{t} & c_{t}\end{array}\right]^{\prime}$, which includes the growth rate of industrial production (denoted $y$ ), the unemployment rate $(u)$, the rate of inflation $(\pi)$, and a commodity price inflation rate (c). ${ }^{7}$ As is now common in the VAR literature, commodity prices are included to control for expected future inflation. Production growth and unemployment are measured as deviations from a linear trend as a crude approximation for changes in potential output. Production growth and inflation rates are always reported on an annualized basis. The policy variable $i$ is taken to be the federal funds rate.

The reduced form of this system can be estimated and the structural coefficients recovered with a sufficient number of identification assumptions. However, calculating the optimal funds rate does not require full identification of the system. Instead, it is only necessary to impose the timing assumption that the Fed can respond to contemporaneous variables in the economy when setting the funds rate, but that the funds rate does not have a contemporaneous impact on the economy. This assumption is commonly used and is reasonable for the U.S. given that the monthly frequency of the data. In terms of the system of equations above, this assumption imposes that $\mathbf{b}_{0}=0$.

The sample is chosen based on the stability of the VAR coefficients for the non-policy variables, so that the VAR accurately measures the dynamic behavior of the economy. While the presence of a structural change in late 1979 has been previously documented, the VAR

\footnotetext{
${ }^{7}$ More specifically, the measure of inflation is based on the CPI less shelter, and commodity price inflation is based on the PSCCOM index from Citibase.
} 
coefficients of the non-policy variables are quite unstable in the early 1980's as well. Because the exercise makes comparisons to the volatility of the actual funds rate, it may also be desirable to exclude the episode of non-borrowed reserves targeting that occurred between 1979:10 and 1982:10. ${ }^{8}$ To exclude this episode from all lags in the system, the VAR is estimated over the period 1983:10 to 1996:12. This choice of the beginning of the sample is consistent with the stability of the non-policy equations as indicated by the likelihood ratio test recommended by $\operatorname{Sims}(1980)$. This test rejects structural stability of the non-policy equations over the period 1982:10 to 1983:09 at the .000 significance level, but it cannot reject stability over the 1983:10 to 1984:09 period, with a significance level of .398.

Similarly, the lag structure for the VAR is chosen by testing restrictions on lags using the modified likelihood ratio test. The lag structure must achieve a balance between allowing sufficient dynamics and avoiding over-parameterization. The data does not reject restricting the VAR from 12 to 8 lags. Additional restrictions are rejected, with a significance level of .019 for moving to 6 lags. A lag structure that includes 8 lags is therefore maintained.

The VAR describes both the structural form of the non-policy variables in the economy and the reaction function of the Federal Reserve. The exercise that follows is to calculate the optimal funds rate policy taking as given the structural form of the economy estimated from the VAR. The reaction function of the Fed estimated in the VAR is completely ignored in deriving the optimal policy. The following objective function is assumed for the Fed:

$$
-\frac{1}{2} E_{t}\left\{\sum_{i=1}^{\infty} \beta^{i}\left[\left(\pi_{t+i}-\pi^{*}\right)^{2}+\lambda_{u}\left(u_{t+i}-u^{*}\right)^{2}+\lambda_{y}\left(y_{t+i}-y^{*}\right)^{2}\right]\right\}
$$

where the weights $\lambda_{u}$ and $\lambda_{y}$ determine the relative importance of the deviation of production growth, unemployment, and inflation from their respective targets. The objective function does not contain any explicit reason to smooth interest rates, since the purpose is to investigate whether gradual funds rate movements can be explained without simply assuming that the Fed prefers to act gradually.

The following analysis solves for the policy rule that maximizes this objective subject to the dynamics implied by the VAR estimates. To solve this problem, define a state vector that includes current and lagged values of the non-policy variables and lagged values of the

\footnotetext{
${ }^{8}$ See Bernanke and Mihov(1995) for an analysis of monetary policy under different operating regimes and additional references.
} 
federal funds rate:

$$
\begin{aligned}
\mathbf{X}_{t}= & \left\{y_{t}, y_{t-1}, \ldots, y_{t-8}, u_{t}, u_{t-1}, \ldots, u_{t-8}, \pi_{t}, \pi_{t-1}, \ldots, \pi_{t-8},\right. \\
& \left.c_{t}, c_{t-1}, \ldots, c_{t-8}, i_{t-1}, \ldots, i_{t-8}\right\}
\end{aligned}
$$

The optimal policy will be a solution to the following Bellman equation:

$$
V\left(\mathbf{X}_{t}\right)=\max _{i_{t}}\left\{-\left(\mathbf{X}_{t}-\mathbf{X}^{*}\right)^{\prime} \mathbf{G}\left(\mathbf{X}_{t}-\mathbf{X}^{*}\right)+\beta E_{t}\left[V\left(\mathbf{X}_{t+1}\right)\right]\right\}
$$

subject to

$$
\mathbf{X}_{t+1}=\mathbf{F} \cdot \mathbf{X}_{t}+\mathbf{H} \cdot i_{t}+\mathbf{J}+\mu_{t+1} .
$$

The per-period loss function is expressed in a general quadratic form. $\mathbf{G}$ is a matrix of zeros except for the diagonal elements corresponding to contemporaneous production growth, unemployment, and inflation, which contain the relative weights. The dynamics of the state vector is governed by the matrix $\mathbf{F}$ and the vectors $\mathbf{H}$ and $\mathbf{J}$, which are composed of the point estimates of the coefficients from the VAR. All of the uncertainty in this problem enters through an additive stochastic vector $\mu_{t+1}$.

Since the per-period payout is quadratic and the dynamics are linear, the value function will have the following form:

$$
V(\mathbf{X})=\mathbf{X}^{\prime} \Lambda \mathbf{X}+2 \mathbf{X}^{\prime} \omega+\rho
$$

It can be shown that the solution to this problem is given by

$$
i_{t}^{a}=-\left(\mathbf{H}^{\prime} \Lambda \mathbf{H}\right)^{-1}\left(\mathbf{H}^{\prime} \Lambda \mathbf{F} \cdot \mathbf{X}_{t}+\mathbf{H}^{\prime} \Lambda \mathbf{J}+\mathbf{H}^{\prime} \omega\right)
$$

with $i^{a}$ denoting the solution under additive uncertainty. The matrix $\Lambda$ must satisfy the Riccati equation

$$
\Lambda=-\mathbf{G}+\beta \mathbf{F}^{\prime} \Lambda \mathbf{F}-\beta \mathbf{F}^{\prime} \Lambda \mathbf{H}\left(\mathbf{H}^{\prime} \Lambda \mathbf{H}\right)^{-1} \mathbf{H}^{\prime} \Lambda \mathbf{F}
$$

and $\omega$ satisfies

$$
\begin{aligned}
\omega= & \left(\mathbf{I}-\beta \mathbf{F}^{\prime}\left(\mathbf{I}-\boldsymbol{\Lambda} \mathbf{H}\left(\mathbf{H}^{\prime} \boldsymbol{\Lambda} \mathbf{H}\right)^{-1} \mathbf{H}^{\prime}\right)\right)^{-1} \\
& \left(\mathbf{G X}^{*}+\beta \mathbf{F}^{\prime} \boldsymbol{\Lambda}\left(\mathbf{I}-\mathbf{H}\left(\mathbf{H}^{\prime} \boldsymbol{\Lambda} \mathbf{H}\right)^{-1} \mathbf{H}^{\prime} \boldsymbol{\Lambda}\right) \mathbf{J}\right) .
\end{aligned}
$$

In deriving this policy, it is assumed that the structure of the economy is known with certainty by the Fed. In particular, the Fed does not give any consideration to the precision 
of the estimates in the VAR, instead taking the point estimates to truly describe the dynamic structure of the economy. In section 3, the variance of the VAR estimates is considered in the analysis to investigate the effect of parameter uncertainty on the calculated policy.

The policy rule resulting from this exercise is less restrictive than a policy rule of the type advocated by Taylor(1993). Taylor-type rules typically allow the funds rate to react to the output gap and the deviation of inflation from a target, with the lagged funds rate included in the specification to account for the interest rate smoothing observed. Under the calculated policy in equation (1), the federal funds rate is a function of all current and lagged values of the non-policy variables and lagged values of the funds rate. While there have been no attempts to investigate the presence of gradualism using a Taylor-type rule, most estimates of these rules find a very significant effect of lagged interest rates. ${ }^{9}$ However, this finding leaves open the question of whether the effect of lagged interest rates exists in its own right or represents a lagged effect on fundamentals not captured by the assumed rule. The unrestricted structure of the VAR effectively accounts for the impact of lagged rates on the expected path of fundamentals, and therefore permits conclusions about "excess" sensitivity to lagged funds rates.

The behavior of the optimal policy $i^{a}$ will depend on the six parameters in the problem: $\beta, \lambda_{u}, \lambda_{y}, y^{*}, \pi^{*}$, and $u^{*}$. The solution offered in equations (1) through (3) holds when these parameters are constant. ${ }^{10}$ In the results that follow, a discount factor of $\beta=.996$ is imposed. The results are not significantly affected by other reasonable choices of the discount factor. Because production and unemployment are measured as deviations from their potential levels, $y^{*}=0$ and $u^{*}=0 .{ }^{11}$ The remaining three parameters are choice variables of the Fed and are estimated from the actual behavior of the federal funds rate. For any choice of $\lambda_{u}, \lambda_{y}$, and $\pi^{*}$, the policy rule $i^{a}$ can be calculated. The optimal funds rate is then computed by substituting the vector of state variables into the derived rule periodby-period. The estimated parameters minimize the distance between the optimal policy and the actual funds rate, where the distance is measured by the sum of squared deviations. ${ }^{12}$

\footnotetext{
${ }^{9}$ See, for example, the estimates by Clarida, Gali, and Gertler(1997), particularly over the VolckerGreenspan period.

${ }^{10} \mathrm{In}$ particular, the solution above assumes a value function with constant parameters, which requires that the targets do not vary through time. It is because of this that the VAR includes differenced series.

${ }^{11}$ An alternative specification does not detrend production growth and unemployment and sets the targeted values equal to their sample means: $y^{*}=2.69$, and $u^{*}=6.39$. This specification yields similar results.

${ }^{12}$ The parameters cannot be estimated by more conventional methods because the parameter $\Lambda$ is defined
} 
The estimated objective function has the following parameters: $\lambda_{u}=1.0, \lambda_{y}=0.3$, and $\pi^{*}=2.8 \cdot{ }^{13}$ Whereas estimates of Taylor-type rules indicate the speed with which the Fed responds to deviations in the targeted variables, the response speed is a function of both the dynamics of the economy and the preferences of the Fed. The current analysis separates the two components to the extent that the VAR effectively describes the dynamics of the economy, thus providing an informative estimate of the objective function of the Fed. The estimates indicate that the Fed is concerned about deviations in both inflation and real variables from their potential values. Furthermore, inflation and unemployment have equal weights, while additional attention is given to the growth in production. By using these estimated weights, the analysis that follows allows for the most successful description of monetary policy within the class of objective functions assumed.

\subsection{Comparing the Actual and Optimal Funds Rate}

Despite the complexity of the solution in equations (1) through (3), the optimal policy is quite successful at describing the actual behavior of the funds rate. This success is demonstrated in Figure 2, which plots the value of the funds rate predicted by the optimal policy rule given the true state of the economy in each month. In other words, for any particular month the figure graphs the funds rate choice $i^{a}$ given that it has previously implemented the actual funds rate. The calculated policy rule effectively describes the level of the funds rate throughout the sample. However, there is clearly a difference between the behavior of the actual and optimal policies. This is most evident by comparing the volatility of the two series. The standard error of the change in the optimal funds rate is 43.6 basis points, well above the standard error of 28.3 basis points for the actual funds rate change.

The difference in the volatility reflects the fact that funds rate movements are more aggressive under the optimal policy rule. This difference can be seen by comparing the impulse response functions of the two policies to various shocks in the economy. To do so, it is necessary to impose additional identification assumptions that were not required for calculating the optimal policy. The identification chosen assumes that the matrix describing

implicitly by equation (2) and must be solved numerically. As a result, the exercise does not measure the precision of the parameter estimates.

${ }^{13}$ Due to the computing power required for this exercise, these values are searched over a fairly coarse grid, with precision of .10. 


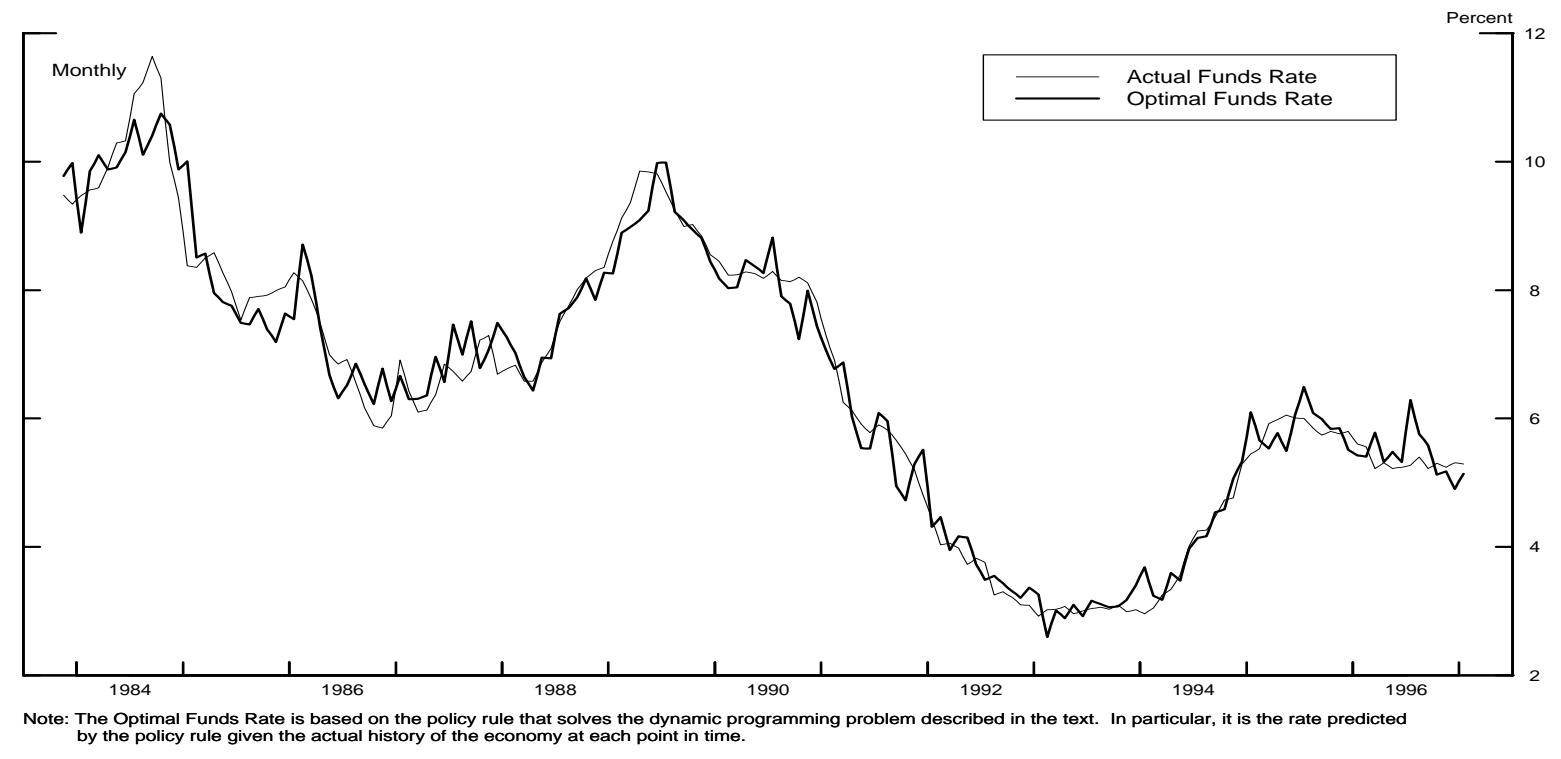

Figure 2: Actual and Optimal Funds Rate under Additive Uncertainty

the contemporaneous interaction of the variables, denoted $\mathbf{A}_{0}$ in the VAR system, is lower triangular. In other words, the identification is achieved through a Choleski decomposition, with the ordering of the variables as $\left\{y_{t}, u_{t}, \pi_{t}, c_{t}, i_{t}\right\}$. Under this identification, Figure 3 displays the impulse response functions of the actual funds rate and the optimal funds rate in response to a shock to each of the five variables in the VAR.

The tendency for the Fed to implement gradual, persistent movements in the funds rate is evident in the response of the actual policy to each of the five shocks in the economy. The Fed appears reluctant to make aggressive changes in the funds rate, choosing instead to adjust the funds rate gradually so that many months often pass before the peak of the funds rate response is reached. Moreover, the funds rate reverts back to its previous level very slowly, so that in several instances it takes years to implement the full response to a one-time shock. These movements are consistent with the gradual funds rate behavior described in the introduction.

However, the impulse response functions of the optimal policy indicate that drawing conclusions about gradualism from the persistence of funds rate movements may be misleading. A substantial portion of this persistence can be accounted for by the dynamic structure of 

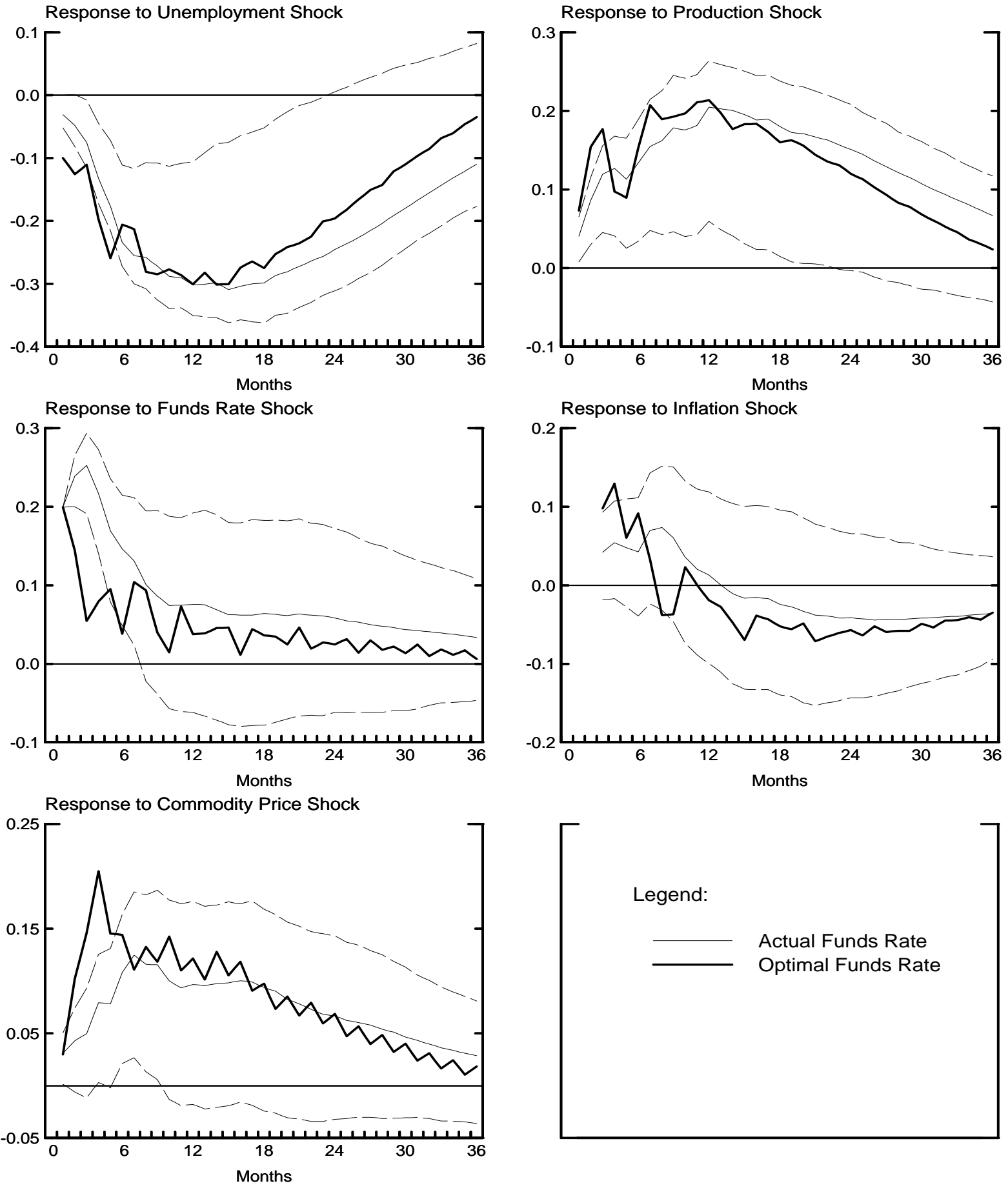

Note: Figures display $90 \%$ confidence intervals for the actual policy.

Figure 3: Impulse Response Functions under Additive Uncertainty 
the economy, even though the Fed has no interest-rate smoothing objective. This is particularly the case in response to shocks to production growth or unemployment, where the optimal policy involves a response that builds over time and slowly reverts, similar to that observed in the data.

Although dynamic structure can explain persistent funds rate movements, the optimal policy responds more aggressively than the observed policy to each of the five shocks in the economy. Even in response to production and unemployment shocks, where the reactions are the most similar, the optimal policy involves a swifter movement of the funds rate immediately following the shock. The actual response instead dampens the immediate change in the funds rate, reaching the optimal response only after 3 to 6 months, and also reverts to its previous level more slowly. Larger deviations arise between the actual and optimal policies in response to the other three shocks. Shocks to inflation and commodity prices warrant sudden increases in the funds rate that peak within 4 months of the shock. ${ }^{14}$ The observed policy instead involves passive increases in the funds rate that do not peak until 7 or 8 months following the shock.

The observed policy maintains a restrained and deliberate speed of adjustment for the funds rate that is similar across all shocks, despite the fact that the optimal reaction speed varies across shocks, suggesting that the Fed is simply reluctant to make aggressive funds rate changes. This behavior is perhaps most apparent in response to shocks to the funds rate itself. Since by definition these shocks are orthogonal to changes in the non-policy variables, there is little reason for the funds rate to remain persistently high. This is reflected in the reaction of the optimal policy, which offsets the funds rate shock very quickly. By contrast, the actual funds rate again only slowly declines to its previous level.

When the uncertainty in the economy is additive, and therefore unrelated to the policy that is implemented, the Fed faces no restraint to responding strongly to movements in the non-policy variables from their targets. As a result, the optimal policy reacts more aggressively than the observed policy in response to developments in the economy. In fact, most of the difference in the two policies arises from the reaction of the funds rate within the few months immediately following a shock. The variance of funds rate changes can be decomposed into the portion explained by the reaction function at different times following

\footnotetext{
${ }^{14}$ The first two observations of the response to a shock to inflation are excluded from the figure. The reason is that the VAR suffers from the "price puzzle," so that the immediate reaction of inflation to funds rate movements is perverse, which affects the immediate response to the inflation shock.
} 
the shock. Table 1 presents the relative variance of funds rate changes under the two policies explained by the reaction function between the shock and the time period indicated.

Table 1: Relative Volatility of Funds Rate Changes

\begin{tabular}{|c||c|c|c|c|c|c|}
\hline Months Following Shock & 1 & 3 & 6 & 12 & 24 & $\infty$ \\
\hline $\operatorname{var}\left(\Delta i^{a}\right) / \operatorname{var}(\Delta i)$ & 1.48 & 2.12 & 2.27 & 2.50 & 2.64 & 2.66 \\
\hline
\end{tabular}

The ratio of the unconditional variances is given by the amount explained by the entire reaction function, denoted $\infty$ in the last column of the table, indicating that the variance of funds rate changes is 2.66 times higher under the optimal policy. ${ }^{15}$ The table demonstrates that a large portion of this difference is explained by the reactions within three months of the shock, from which the variance of funds rate changes is over twice as high under the optimal policy. This finding corresponds to an point made by Cecchetti(1995), who argues that policy should respond quickly to expected inflation since the effect of policy on prices is realized only after a substantial delay. ${ }^{16}$ Similarly, the current analysis indicates that, given the dynamic structure of the economy, monetary policy is expected to move the funds rate strongly immediately following a shock, while the observed reaction of the funds rate is instead dampened.

The difference in the "reaction speed" of the two policies is evident in Figure 4, which depicts the path that the funds rate would have followed had the Fed been implementing the optimal policy throughout this period. In contrast to Figure 2, which resets the state variable $\mathbf{X}$ to its actual value in each month, Figure 4 allows the state variable to evolve according to the estimated dynamics of the non-policy variables and the optimal policy rule, assuming that the economy is subject to the same series of shocks. The persistence observed in the impulse response functions is reflected by persistent directional movements in the optimal funds rate. The dynamic evolution of the non-policy variables warrants directional movements in the funds rate of duration remarkably close to those observed in the data. As a result, it would be incorrect to conclude that the Fed has an interest-rate smoothing objective simply from the tendency for the funds rate to move in one direction over substantial periods of time.

\footnotetext{
${ }^{15}$ This ratio is somewhat different from the ratio of 2.37 that is obtained using the standard deviations from Figure 1, since those were calculated given the observed history of the economy at each point in time.

${ }^{16}$ Cecchetti(1995) performs an exercise similar to the one here, finding that the Fed should react more strongly to various shocks in the economy. He also discusses the amount of uncertainty over the effect of policy on inflation, although he does not incorporate it into this exercise.
} 


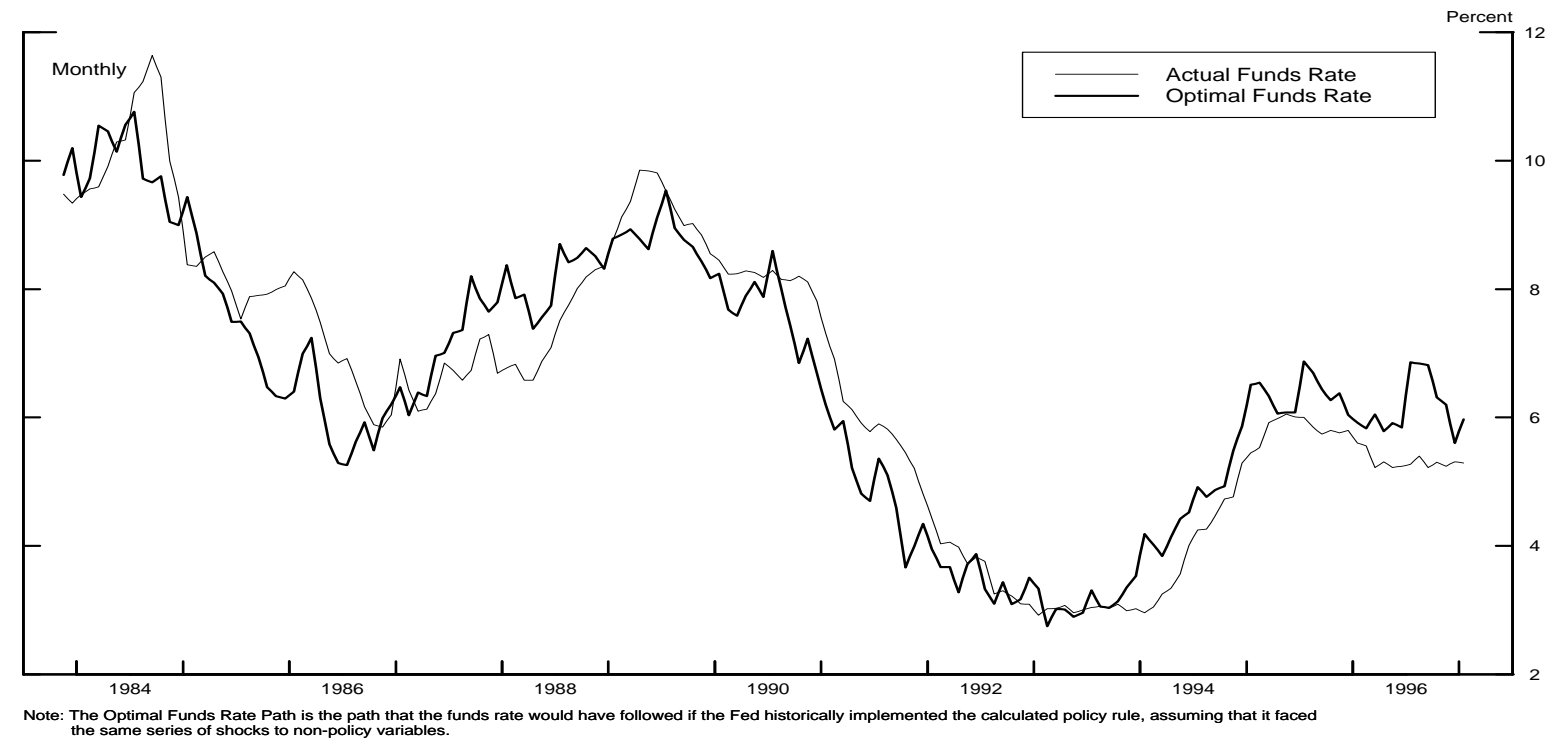

Figure 4: Actual and Optimal Funds Rate Path under Additive Uncertainty

Although broad movements in a particular direction can be explained by the dynamic structure of the economy, the differences between the two paths reflect the tendency for the Fed to smooth the funds rate. As observed in Figure 2, the optimal policy is very volatile relative to the observed policy. Considering these findings, statistics such as the percentage of continuations may only gauge gradualism to the extent that they measure the limited volatility in the funds rate, rather than continued directional movements. In addition, the finding that the optimal policy reacts more aggressively to changes in the economy is reflected in the deviation between the paths. In nearly every directional movement of the funds rate, the optimal policy leads the actual policy ${ }^{17}$ as the tendency to smooth changes in the funds rate causes the Fed to fall behind the optimal funds rate movement.

The gradual behavior depicted in Figures 3 and 4 is effectively described by a partial adjustment model modified to capture inertia in funds rate changes:

\footnotetext{
${ }^{17}$ The only exception is the most recent decline in the funds rate, which involved three target rate changes beginning on $2 / 1 / 95$ that dropped the funds rate 75 basis points.
} 


\section{Partial-Adjustment Model under Additive Uncertainty}

$$
\begin{aligned}
\Delta i_{t}= & 0.210\left(i_{t}^{a}-i_{t-1}\right)+0.394 \Delta i_{t-1} \\
& (4.25) \\
& R^{2}=.255, \text { D.W. }=2.18
\end{aligned}
$$

where $i_{t}^{a}$ is the optimal policy from the calculated rule. This specification presents a parsimonious measure of the extent of interest rate smoothing found in the data. The estimates indicate that the change in the funds rate only partially offsets a deviation from the optimal funds rate, with the lagged change in the funds rate exerting a significant effect on the dynamics. Absent previous funds rate changes, a permanent 100 basis point increase in the optimal funds rate results in a contemporaneous rise in the actual funds rate of only 21 basis points. The funds rate instead moves gradually towards the optimal level, rising 67 basis points after 3 months and 98 basis points after 6 months. ${ }^{18}$

The results reiterate the conclusions reached in this section. The dynamic structure of the economy can explain a large portion of the movements in the federal funds rate over the sample, including the tendency to move in a particular direction over a sustained period of time. However, there is clearly an element of interest-rate smoothing that cannot be captured by the assumed objective function. The volatility of the funds rate is much lower than expected, as the observed policy dampens the changes in the funds rate expected in response to a shock to the economy. In addition, the Fed tends to fall behind the movements in the funds rate that would maximize the objective function assumed, as the funds rate moves only gradually towards the optimal level.

The failure to fully describe the gradual funds rate movements that are observed permits several possible explanations. One is that the Fed truly has an interest-rate smoothing objective, so that the loss function assumed above is incorrect. However, there is not a strong justification for modifying the objective function with this term, beyond the fact that it more successfully fits the data. ${ }^{19}$ The failure to fully explain funds rate movements could instead reflect a misspecification of the problem confronting the Fed. The above analysis

\footnotetext{
${ }^{18}$ Of course this specification imposes some structure on the dynamics of the adjustment. Similar dynamics are obtained in a specification with unrestricted dynamics. Some of the gradual behavior estimated in the partial-adjustment equation could be attributed to mismeasurement of the optimal funds rate. This equation is later estimated in the case with parameter uncertainty, indicating that this component of the problem is instead responsible for much of the slow adjustment speed.

${ }^{19}$ Several justifications for this term have been offered in the literature on monetary policy, including pro-
} 
assumes that the structure of the economy is known with certainty, with all of the stochastic variation in the economy entering through an additive disturbance. An important element of policymaking is the fact that the structure of the economy is not known, but instead must be estimated imprecisely. The next section investigates whether parameter uncertainty can in fact account for the gradual movements in the funds rate observed.

\section{Incorporating Parameter Uncertainty}

While the dynamic structure of the economy cannot by itself account for the gradual behavior of the funds rate, uncertainty over the dynamic structure should also have a significant impact on monetary policy. The effect of parameter uncertainty on the optimal policy choice was first analyzed by Brainard(1967), who found that uncertainty regarding the effect of the policy instrument leads the policymaker to use the instrument less aggressively. More generally, parameter uncertainty limits the deviation of the policy instrument from the level that minimizes the variance of its effect. Recent work has focused on this effect in dynamic models in which the uncertainty is determined by a learning process. ${ }^{20}$ In these models, the problem facing the policymaker is to estimate a set of parameters that may be stochastically changing through time. However, stability tests for the VAR coefficients indicate that the structural form of the economy is stable over this sample. It may therefore be more relevant to concentrate on the parameter uncertainty arising exclusively from the imprecise estimation of the structural form of the economy.

While the exercise in section 2 incorporates only the point estimates of the coefficients in deriving the optimal policy, the exercise that follows also considers the information contained in the variance-covariance matrix of the point estimates. By measuring the parameter uncertainty using the variance-covariance matrix from the VAR, the analysis focuses on parameter uncertainty arising exclusively from imprecise estimation, assuming that the structure of the VAR is constant over this sample.

tecting the banking sector against financial crisis (see Goodfriend(1987) and Cukierman(1991)) and concern over "whipsawing" financial markets (see Goodfriend(1991)).

${ }^{20}$ See, for example, papers by Wieland(1997) and Sack(1998). Wieland(1997) offers a model in which uncertainty over the parameters of the Phillips curve leads to a muted response of the funds rate to the deviation of inflation from its target. Sack(1998) presents a model in which learning about the policy multiplier causes the Fed to limit the deviation of the funds rate from its previous level. 


\subsection{Optimal Policy under Parameter Uncertainty}

The problem in section 2 assumes that all uncertainty in the economy is captured by an additive stochastic disturbance to the state variables. Because the objective function is quadratic, additive uncertainty has no effect on the calculated policy - that is, certaintyequivalence holds. The optimization problem that incorporates uncertainty in the dynamics of the state variable is substantially more difficult. However, the problem can be simplified greatly by imposing an additional restriction and redefining the state variable of the problem. Consider a new vector of state variables defined as $\widehat{\mathbf{X}}_{t}=E_{t-1}\left[\mathbf{X}_{t}\right]$, or the projection of the state variable $\mathbf{X}_{t}$ on time $t-1$ information. The policy choice of the Fed is now constrained to be a function of this new state variable. Because this projection can be written as a linear combination of $\mathbf{X}_{t-1}$, this restriction simply corresponds to the other "timing" assumption that is commonly made - that the Fed cannot respond to shocks to the nonpolicy variables within the month. The impulse response functions of the actual policy do not change significantly when this restriction is imposed.

Equipped with the new state variable, the calculation of the optimal policy is straightforward. The simplification comes because the effect of the parameter uncertainty can now be included in the per-period loss function for the Fed, while the dynamic evolution of the state variable no longer involves stochastic coefficients. The solution to the optimization problem will satisfy the following Bellman equation:

$$
V\left(\widehat{\mathbf{X}}_{t}\right)=\max _{i_{t}}\left\{-\left(\widehat{\mathbf{X}}_{t}-\mathbf{X}^{*}\right)^{\prime} \mathbf{G}\left(\widehat{\mathbf{X}}_{t}-\mathbf{X}^{*}\right)-\left(\widehat{\mathbf{X}}_{t}^{\prime} \mathbf{K} \widehat{\mathbf{X}}_{t}+2 \widehat{\mathbf{X}}_{t}^{\prime} \mathbf{L}\right)+\beta\left[V\left(\widehat{\mathbf{X}}_{t+1}\right)\right]\right\} .
$$

subject to

$$
\widehat{\mathbf{X}}_{t+1}=\mathbf{F} \cdot \widehat{\mathbf{X}}_{t}+\mathbf{H} \cdot i_{t}+\mathbf{J}+\mu_{t+1}
$$

The transition matrices still consist of the point estimates from the VAR, since these determine the path of the expected state variable. Since the per-period loss function involves the expected squared deviations of the targeted variables, it can be broken into two components. The first term involves the weighted sum of the squared value of the expected deviations from the targets. The second term is a weighted average of the variance of the targeted variables, given by the expression $\widehat{\mathbf{X}}_{t}^{\prime} \mathbf{K} \widehat{\mathbf{X}}_{t}+2 \widehat{\mathbf{X}}_{t}^{\prime} \mathbf{L}$ in equation (4). This expression measures the amount of uncertainty that is associated with a particular expected value of the state variable. In particular, the matrix $\mathbf{K}$ is given by $\mathbf{K}=\Sigma_{\beta(\pi)}+\lambda_{u} \Sigma_{\beta(u)}+\lambda_{y} \Sigma_{\beta(y)}$ where $\Sigma_{\beta(n)}$ represents the covariance matrix between the coefficients in the equation describing variable 
$n$ corresponding to the state vector. The matrix $\mathbf{L}$ is constructed in a similar manner and measures the covariance of the parameter estimates with the estimated constant. The importance of this term is that it relates the variance of the targeted variables to the choice of the funds rate. The interest rate choice determines the expected state variable next period, which affects the variance of the target variables as determined by the covariance matrix of the parameter estimates in the VAR.

The solution to this problem is similar to that in the case of additive uncertainty. The optimal policy under parameter uncertainty, $i^{p}$, will again be given by equation (1), repeated here for convenience:

$$
i_{t}^{p}=-\left(\mathbf{H}^{\prime} \Lambda \mathbf{H}\right)^{-1}\left(\mathbf{H}^{\prime} \Lambda \mathbf{F} \cdot \widehat{\mathbf{X}}_{t}+\mathbf{H}^{\prime} \Lambda \mathbf{J}+\mathbf{H}^{\prime} \omega\right)
$$

The difference from the previous case arises in the equations determining $\Lambda$ and $\omega$. Equations (2) and (3) are replaced by the following equations:

$$
\Lambda=-\mathbf{G}-\mathbf{K}+\beta \mathbf{F}^{\prime} \Lambda \mathbf{F}-\beta \mathbf{F}^{\prime} \Lambda \mathbf{H}\left(\mathbf{H}^{\prime} \Lambda \mathbf{H}\right)^{-1} \mathbf{H}^{\prime} \Lambda \mathbf{F}
$$

and

$$
\begin{aligned}
\omega= & \left(\mathbf{I}-\beta \mathbf{F}^{\prime}\left(\mathbf{I}-\mathbf{\Lambda} \mathbf{H}\left(\mathbf{H}^{\prime} \boldsymbol{\Lambda} \mathbf{H}\right)^{-1} \mathbf{H}^{\prime}\right)\right)^{-1} \\
& \left(\mathbf{G X}^{*}-\mathbf{L}+\beta \mathbf{F}^{\prime} \boldsymbol{\Lambda}\left(\mathbf{I}-\mathbf{H}\left(\mathbf{H}^{\prime} \boldsymbol{\Lambda} \mathbf{H}\right)^{-1} \mathbf{H}^{\prime} \boldsymbol{\Lambda}\right) \mathbf{J}\right)
\end{aligned}
$$

The difference in the two problems appears modest, captured simply by the presence of the $\mathbf{K}$ matrix in equation (6) and the $\mathbf{L}$ vector in equation (7).

The solution to the dynamic programming problem assumes that the matrices determining the uncertainty in the problem are constant. Because of this, the solution is said to entail passive learning. In implementing the calculated policy, the parameter uncertainty will decline through time as the Fed accumulates additional observations with which to estimate the VAR. The optimal solution depends on the level of the uncertainty but does not take into consideration that the choice of the funds rate affects the information contained in the additional observation it will obtain. ${ }^{21}$

The parameters of the objective function of the Fed are estimated using the same methodology as in section 2. The estimated parameters are as follows: $\lambda_{u}=1.25, \lambda_{y}=.25$, and

\footnotetext{
${ }^{21}$ The optimal solution that considers the impact on learning is often referred to as active learning. Wieland(1996) offers an interesting discussion of the difference between the optimal policy choice under active and passive learning in a general framework.
} 


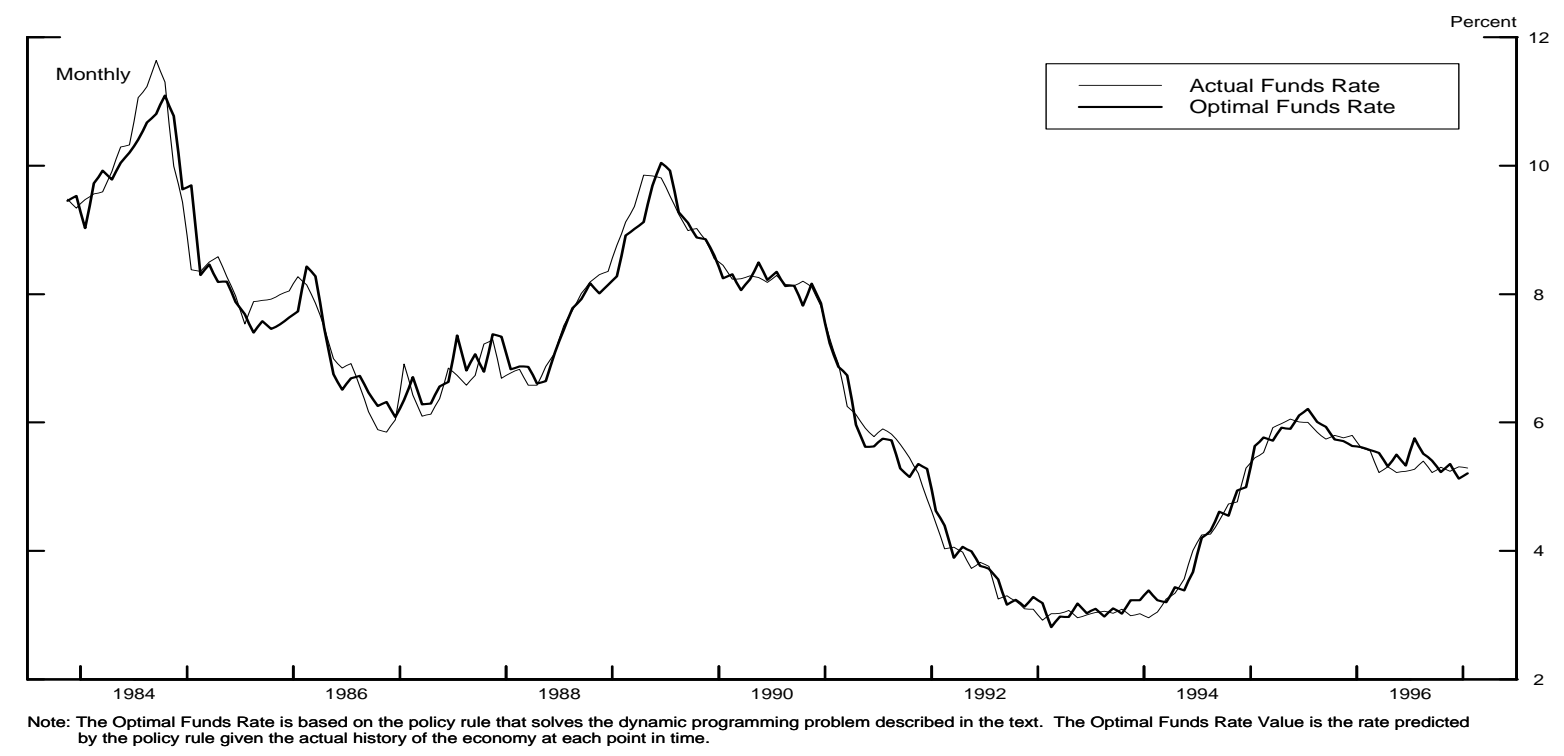

Figure 5: Actual and Optimal Funds Rate under Parameter Uncertainty

$\pi^{*}=2.9$. Including parameter uncertainty therefore does not result in a dramatic revision of these estimates. The weight on unemployment deviations increases, while the weight on production growth and the inflation target are only slightly changed.

\subsection{A Smoother Optimal Funds Rate}

The optimal policy under parameter uncertainty is very successful at describing the dynamic behavior of the funds rate. This is demonstrated in Figure 5, which displays the optimal value of the funds rate for the case of parameter uncertainty. The optimal policy is no longer excessively volatile as found in Figure 2. The standard deviation of optimal funds rate changes falls from 43.2 basis points to 32.1 , much closer to the observed value of 28.3.

In addition to reducing the volatility, parameter uncertainty limits the deviation between the optimal policy and actual policy found under additive uncertainty. To emphasize the difference from the observed policy, Figure 6 characterizes the impulse response functions reported in Figure 3 in terms of the deviation between the optimal response and the actual response. The deviation clearly depicts the tendency for the optimal policy to overreact. For example, in response to an unemployment shock, the line denoted $i^{a}-i$ indicates that the 

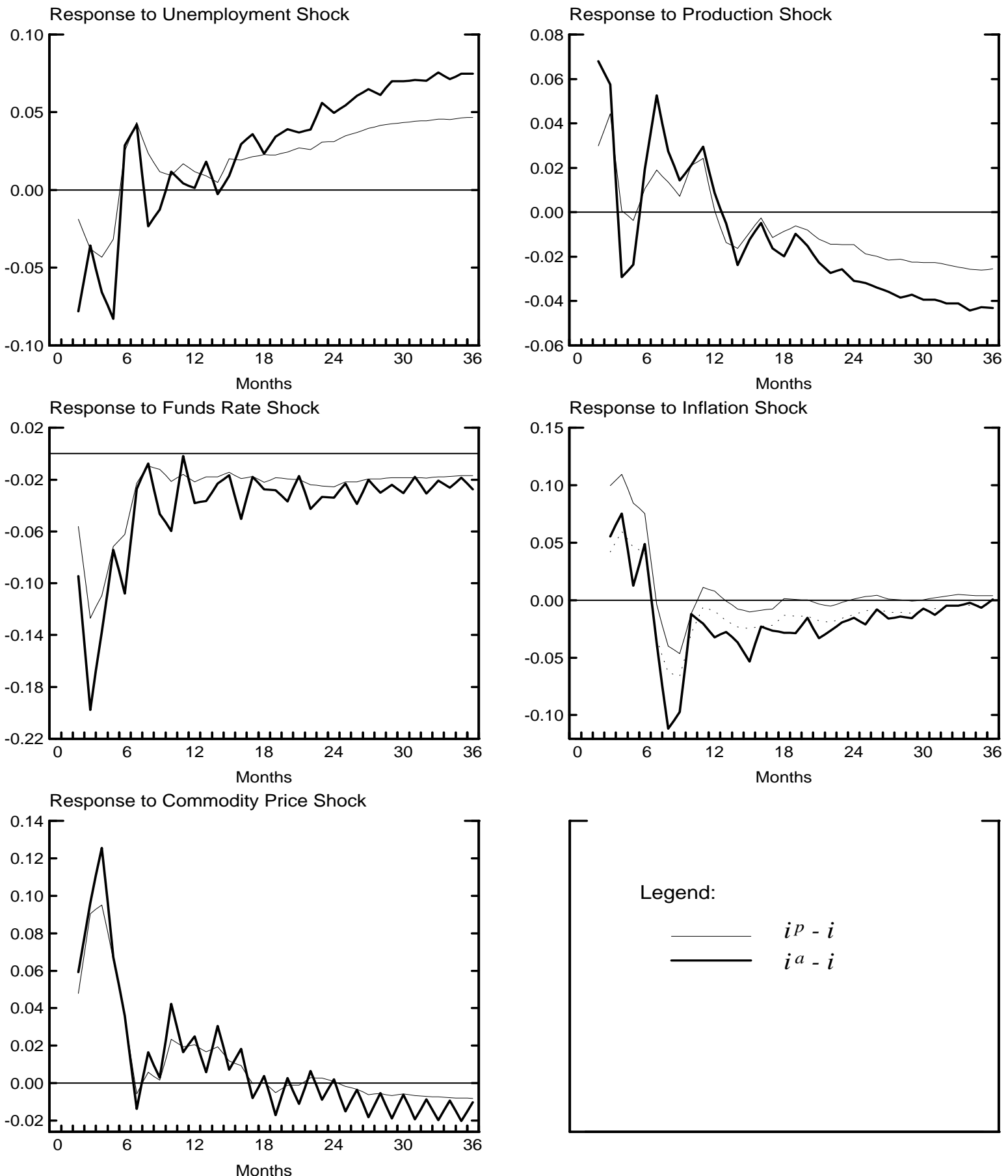

Note: The thick line displays the difference between the optimal policy under additive uncertainty and the actual policy.

The thin line displays the difference between the optimal policy under parameter uncertainty and the actual policy.

Figure 6: Deviations of the Impulse Response Functions 
optimal funds rate falls more quickly than the actual funds rate, and the actual funds rate catches up only after 6 months. A year following the shock, the actual funds rate falls below the optimal funds rate, since the dampened initial reaction of the actual policy requires that it returns to its previous level less quickly. This pattern is observed in response to every shock in the economy, again describing the gradual adjustment of the funds rate described in section 2 .

The line denoted $i^{p}-i$ presents the deviation for the optimal policy under parameter uncertainty. The figure indicates that a considerable portion of the gradual funds rate movements that could not be explained by dynamic structure are in fact explained by the parameter uncertainty that the Fed faces. As indicated by the response of the line $i^{p}-i$, parameter uncertainty limits the overreaction of the optimal policy following a shock and accounts for the tendency of the actual policy to revert more quickly. The only exception is in response to an inflation shock, where the response of $i^{p}-i$ indicates a stronger overreaction in the case of parameter uncertainty. This exception results from a change in the impulse response function of the actual policy when the additional identification restrictions are imposed. In all other cases, the response of actual policy is unaffected by the additional restriction. However, the funds rate has a much weaker response to an inflation shock when the restriction is imposed. This may result from the imprecise estimation of that response, as indicated by the large confidence intervals in Figure 3. The dotted line in Figure 6 demonstrates the overreaction of $i^{p}$ relative to the funds rate response without the restriction, indicating that parameter uncertainty dampens the overreaction as in the response to the other shocks.

The ability of the optimal policy under parameter uncertainty to describe gradual funds rate movements can also be gauged using the partial adjustment model described in section 2 :

\section{Partial-Adjustment Model under Parameter Uncertainty}

$$
\begin{aligned}
\Delta i_{t}= & 0.374\left(i_{t}^{p}-i_{t-1}\right)+0.329 \Delta i_{t-1} \\
& (4.46) \\
& R^{2}=.263, \text { D.W. }=2.14
\end{aligned}
$$

Deviations between the calculated policy and the actual policy are now smaller and are offset more quickly. The funds rate closes $95 \%$ of a deviation from its optimal value within three months, as opposed to the $67 \%$ found in the case of additive uncertainty. In addition, the 
standard deviation of the difference between the optimal and actual level of the funds rate decreases from 41.2 basis points under the policy $i^{a}$ to 28.8 basis points under the policy $i^{p}$. This improvement reflects the decline in the aggressiveness of the optimal policy, bringing it closer to the dynamic behavior of the observed policy.

\subsection{The Effect of Parameter Uncertainty}

The above results indicate that the policy $i^{p}$ is much more successful at describing the dynamic behavior of the funds rate. The aggressive movements in the funds rate that characterized the policy $i^{a}$ are now dampened. The policy $i^{p}$ instead smoothes the response of the funds rate, as observed in the actual behavior of the Federal Reserve. This difference in the two policies arises because the aggressive interest rate movements found under additive uncertainty induce a substantial amount of variance in the targeted variables when the VAR coefficients are not precisely known. This explanation is examined in more detail in this section.

As a general rule, parameter uncertainty biases the optimal choice of the funds rate towards the level that minimizes the variance of the targeted variables. The per-period loss function from the exercise above involves a weighted sum of the expected squared deviation of the targeted variables from their respective targets. Each of these components can be decomposed into the sum of the squared expected deviation from the target and the variance of the variable. Using inflation as an example, $E_{t}\left[\left(\pi-\pi^{*}\right)^{2}\right]=\left(\widehat{\pi}-\pi^{*}\right)^{2}+\operatorname{var}(\pi)$. In the presence of parameter uncertainty, the variance of the targeted variable will be affected by the policy choice, which will be taken into consideration in formulating the policy decision.

In the case where parameter uncertainty is measured by the variance-covariance matrix of the VAR coefficients, the variance associated with a funds rate choice can be found analytically. Consider the equation in the VAR that determines the rate of inflation next period. The regressors determining inflation can be partitioned into two groups, the funds rate $i$ and all other regressors $Z_{1}$. The equation can be written as

$$
\pi=Z_{1} \cdot \beta_{1}+i \cdot \beta_{2}+\epsilon
$$

where $Z_{1}$ is a matrix containing the entire history of the regressors and $i, \pi$, and $\epsilon$ are vectors containing all observations of the funds rate, inflation, and the residual, respectively. Based on standard results regarding partitioned regressions, the estimates of the regressors can be 
written as follows:

$$
\begin{aligned}
& \widehat{\beta}_{2}=\left(i^{\prime} M_{1} i\right)^{-1} \cdot\left(i^{\prime} M_{1} \pi\right) \\
& \widehat{\beta}_{1}=\left(Z_{1}^{\prime} Z_{1}\right)^{-1} Z_{1}^{\prime}\left(\pi-i \cdot \widehat{\beta}_{2}\right)
\end{aligned}
$$

where $M_{1}=\left(I-Z_{1}\left(Z_{1}^{\prime} Z_{1}\right)^{-1} Z_{1}^{\prime}\right)$. Suppose that the current values of all other regressors are observed and equal to $Z_{1}^{o}$. For a particular choice of the funds rate, $i^{o}$, the predicted value of inflation is given by

$$
\pi^{o}=Z_{1}^{o} \cdot \widehat{\beta}_{1}+i^{o} \cdot \widehat{\beta}_{2}
$$

The Fed is of course concerned with choosing the funds rate to move the predicted value of inflation close to its target. In the case of additive uncertainty, this is the only objective that matters, since the variance of the targeted variable is independent of policy. However, with parameter uncertainty, the variance of inflation next period is affected by the policy choice because of the imprecision in the coefficient estimates $\widehat{\beta}_{1}$ and $\widehat{\beta}_{2}$. It can be shown that the variance of inflation is given by the following expression:

$$
\begin{gathered}
\sigma^{2} Z_{1}^{o}\left(Z_{1}^{\prime} Z_{1}\right)^{-1} Z_{1}^{\prime}\left[I+i\left(i^{\prime} M_{1} i\right)^{-1} i^{\prime}\right] Z_{1}\left(Z_{1}^{\prime} Z_{1}\right)^{-1} Z_{1}^{o \prime}+ \\
\sigma^{2} i^{o}\left(i^{\prime} M_{1} i\right)^{-1} i^{o \prime}-2 Z_{1}^{o}\left(Z_{1}^{\prime} Z_{1}\right)^{-1} Z_{1}^{\prime} i\left(i^{\prime} M_{1} i\right)^{-1} i^{o \prime}+\sigma^{2}
\end{gathered}
$$

The choice of the funds rate that minimizes this expression is

$$
\begin{aligned}
i^{*} & =Z_{1}^{o}\left(Z_{1}^{\prime} Z_{1}\right)^{-1} Z_{1}^{\prime} i \\
& =Z_{1}^{o} \widehat{\gamma}
\end{aligned}
$$

where $\hat{\gamma}=\left(Z_{1}^{\prime} Z_{1}\right)^{-1} Z_{1}^{\prime} i$ is the vector of coefficients from the projection of the funds rate on the regressors in $Z_{1}$. These regressors include the current and lagged non-policy variables and the lagged funds rate, so that the coefficient vector $\widehat{\gamma}$ corresponds to the estimated reaction function of the Fed. ${ }^{22}$ Even though it has been completely ignored in deriving the optimal policy, the estimated reaction function plays a critical role in determining this policy. The choice of the funds rate that minimizes the variance of the targeted variables arising from parameter uncertainty is the rate predicted by the policy rule that the Fed has historically followed. Intuitively, by following a particular policy rule, the Fed learns about

\footnotetext{
${ }^{22}$ There is a slight difference since equation (12) excludes the last lag that is included in the estimated reaction function.
} 
the response of the economy when it chooses policy according to that rule. This is true for each of the targeted variables, so that the result applies under any set of weights for the objective function. ${ }^{23}$

As a result, the Fed is unwilling to deviate substantially from the policy rule that has been previously implemented. Current policymakers are inhibited by past policy choices, since altering the policy response results in a higher expected variance of the targeted variables. Parameter uncertainty can therefore account for gradual funds rate movements because the Fed has historically smoothed interest rates. To act more aggressively now would push the Fed uncomfortably far away from the region where the response of the economy has been established. This accounts for the gradual funds rate movements under the optimal policy that are demonstrated in Figures 5 and 6 . The policy $i^{a}$ results in a very high expected variance of the targeted variables because the Fed has not historically implemented such aggressive funds rate changes. The policy $i^{p}$ involves a substantially lower volatility of the funds rate to account for the effect of parameter uncertainty.

The effect of parameter uncertainty becomes apparent when the performance of the calculated policy rules is compared. The comparison is conducted using 500 simulations of the behavior of the economy first under the assumption that the coefficient matrix is constant, so that there is additive uncertainty only, and then under the assumption that the coefficients are stochastic, drawn from the distribution estimated in the VAR. For each targeted variable, the squared expected deviation from target and the conditional variance are computed at each point in time, and the average values of these variables are calculated for that iteration. The median values of these variables across the iterations are then computed, as well as the median loss function from the exercise above. However, these statistics cannot be directly compared for the policy rules $i^{a}$ and $i^{p}$ because of the different identification assumptions required, as the policy $i^{a}$ reacts to contemporaneous shocks while the policy $i^{p}$ does not. Instead, the performance of these rules is compared by calculating the value of each statistic relative to the value resulting from the estimated policy rule that is restricted to react to the same information set. The relative values of these statistics are presented in Table 2.

\footnotetext{
${ }^{23}$ This implication is true for minimizing the variance of the targeted variables one period ahead. In the dynamic problem, the variance-minimizing policy differs because the Fed also has an incentive to move the non-policy variables to the level that minimizes the variance.
} 
Table 2: Performance of Policy Rules

Relative to the VAR Policy

\begin{tabular}{|c||c|c||c|c|}
\hline \multicolumn{1}{|c||}{ Uncertainty Type: } & \multicolumn{2}{c||}{ Additive } & \multicolumn{2}{c|}{ Parameter } \\
\hline Policy: & $i^{a}$ & $i^{p}$ & $i^{a}$ & $i^{p}$ \\
\hline \hline$\left(\widehat{y}-y^{*}\right)^{2}$ & 0.71 & 0.81 & 0.86 & 0.80 \\
\hline$\left(\widehat{\pi}-\pi^{2}\right)^{2}$ & 0.83 & 0.81 & 0.97 & 0.79 \\
\hline$\left(\widehat{u}-u^{*}\right)^{2}$ & 1.00 & 0.95 & 1.24 & 1.00 \\
\hline \hline $\operatorname{var}(y)$ & 1.00 & 0.99 & 1.26 & 1.02 \\
\hline $\operatorname{var}(\pi)$ & 0.99 & 1.01 & 1.28 & 1.03 \\
\hline $\operatorname{var}(u)$ & 1.00 & 1.00 & 1.29 & 1.03 \\
\hline \hline $\operatorname{loss}$ & 0.90 & 0.92 & 1.12 & 0.94 \\
\hline
\end{tabular}

The results under the assumption of additive uncertainty demonstrate the benefits of an aggressive policy rule. By implementing a strong funds rate reaction to the non-policy variables, the policy rule $i^{a}$ is very successful at reaching the target values for $y, \pi$, and $u$ in expected terms. This policy reduces the squared expected deviations of production growth and inflation by substantial margins, while maintaining an expected unemployment deviation that is comparable to that found under the VAR rule. The VAR policy instead smoothes the funds rate, therefore dampening its responsiveness to movements in the targeted variables and permitting larger expected deviations to arise. Under the assumption that all of the uncertainty in the economy is additive, the conditional variances of the targeted variables are determined only by the variances of the additive disturbance terms and are therefore unaffected by the high funds rate volatility under the policy $i^{a}$. As a result, the policy rule $i^{a}$ substantially outperforms the VAR policy, reducing the loss function by $10 \%$. If facing additive uncertainty only, the results indicate that the Fed should engage in a more aggressive policy.

The policy rule $i^{p}$ involves more gradual funds rate movements than the policy $i^{a}$ but still reacts more aggressively than the actual policy rule. As a result, the policy $i^{p}$ also outperforms the VAR policy by an impressive $8 \%$ in the case of additive uncertainty. However, since this policy does engage in some interest rate smoothing, the improvement is more limited than the $10 \%$ margin found under the policy $i^{a}$.

The relative performance of the policies is dramatically different once the simulation 
allows for an uncertain dynamic structure. As indicated in the last two columns of the table, the volatile funds rate movements under the policy $i^{a}$ result in large increases in the conditional variances of the targeted variables. In contrast, by implementing gradual funds rate movements, the policy rule $i^{p}$ does not result in a similar increase in the conditional variances. Note also that the squared expected deviations resulting from the policy $i^{p}$ are similar to those found under additive uncertainty, while the deviations increase under the policy $i^{a}$. This occurs because the volatility resulting from the policy $i^{a}$ leads to simulated paths of the economy that can be extremely different from any state that has been historically observed. The aggressive policy $i^{a}$ is clearly no longer optimal, resulting in a loss function that is $12 \%$ higher than the loss under the VAR policy. The gradual policy $i^{p}$ instead continues to outperform the observed policy, reducing the loss function by $6 \%$ over the VAR policy. The relative performance of these rules indicates that the tendency to smooth interest rates can be explained by the uncertainty that would be generated by aggressive interest rate changes.

\section{Conclusion}

Gradual movements in the federal funds rate do not necessarily indicate that the Federal Reserve has an interest-rate smoothing incentive. Dynamic structure and parameter uncertainty can account for a considerable portion of the gradual funds rate movements that are observed. The intertemporal behavior of the targeted variables causes the funds rate to move in a particular direction over substantial periods of time. However, under additive uncertainty, expected path of the funds rate is much more volatile and reacts to changes in the economy more aggressively than the observed funds rate. This smoothing of the interest rate can be explained by the fact that the Fed does not perfectly know the structure of the economy. Uncertainty arising from imprecise estimation of the VAR coefficients is minimized at the level of the funds rate predicted by the policy rule that has been historically implemented. An aggressive policy would result in high expected variance for the targeted variables because the Fed has traditionally smoothed the funds rate. The policy rule that accounts for parameter uncertainty therefore reacts to changes in the state of the economy with gradual movements in the funds rate, which reduces the excess volatility of the optimal policy and limits the deviation of this policy from the observed level of the funds rate. 
Although the uncertain dynamic structure results in gradual funds rate movements, there remains an element of interest-rate smoothing that cannot be explained in this exercise. By controlling for the effects of dynamic structure and parameter uncertainty, the exercise provides a measure of the degree of interest-rate smoothing that is inconsistent with the objective function assumed. The actual policy continues to react with smaller funds rate changes to each of the five shocks in the economy. Moreover, the funds rate still has the tendency to trail the optimal policy during directional movements. However, the volatility of actual funds rate changes is only 4 basis points below that of the optimal policy, at 28.3 as opposed to 32.1. In addition, deviations from the optimal policy are limited and are offset quickly, typically within 3 months.

There are several possible explanations for the interest-rate smoothing that remains. The objective function that is assumed imposes an equal weighting between squared expected deviations and the variance of the targeted variables. An objective function that places more weight on the variance term would lead to a larger dependence on historical policy and might therefore more successfully describe interest-rate smoothing. Another possibility is that the parameter uncertainty does not arise solely from imprecise estimation. If the parameters are themselves stochastic, the effect of parameter uncertainty will differ in a manner depending on the evolution of these parameters. In this case it is possible to generate more dependence on lagged interest rates than captured by the variance-covariance matrix of the parameter estimates. However, it may not be necessary to find alternative explanations of the remaining interest-rate smoothing. The results presented in section 3 are calculated measuring the parameter uncertainty by the variance-covariance matrix of the coefficient estimates as of December 1996. Since the Fed did not have the benefit of all of these observations, it faced a greater degree of parameter uncertainty when formulating its policy throughout the sample. The degree of interest-rate smoothing found in the sample is therefore expected to exceed the amount explained in the analysis. Unfortunately, the sample is not sufficiently long to test some of the interesting implications that concern the variation in the uncertainty through time. 


\section{References}

[1] Ball, Lawrence. Efficient Rules for Monetary Policy. NBER Working Paper \#5952 (1997).

[2] Bernanke, Ben and Alan Blinder. The Federal Funds Rate and the Channels of Monetary Transmission. American Economic Review 82 (1992), 901-921.

[3] Bernanke, Ben and Ilian Mihov. Measuring Monetary Policy. Mimeo, Princeton University (1995).

[4] Brainard, William. Uncertainty and the Effectiveness of Policy. American Economic Review, Papers and Proceedings 57 (1967), 411-425.

[5] Cecchetti, Stephen G. Inflation Indicators and Inflation Policy. NBER Macroeconomics Annual (1995), 189-219.

[6] Clarida, Richard, Jordi Gali, and Mark Gertler. Monetary Policy Rules and Macroeconomic Stability: Evidence and Some Theory. Mimeo (1997).

[7] Cukierman, Alex. Why Does the Fed Smooth Interest Rates? in Michael T. Belognia, ed., Monetary Policy on the 75th Anniversary of the Federal Reserve System (1991), 111-147.

[8] Fuhrer, Jeffrey C. Inflation/Output Variance Trade-Offs and Optimal Monetary Policy. Journal of Money, Credit, and Banking 29 (1997), 214-234.

[9] Fuhrer, Jeffrey C. and George R. Moore. Monetary Policy Trade-offs and the Correlation between Nominal Interest Rates and Real Output. American Economic Review 85 (1995), 219-239.

[10] Goodfriend, Marvin. Interest Rates and the Conduct of Monetary Policy. CarnegieRochester Conference Series on Public Policy 34 (1991), 7-30.

[11] Goodfriend, Marvin. Interest Rate Smoothing and Price Level Trend-Stationarity. Journal of Monetary Economics 19 (1987), 335-348.

[12] Goodhart, Charles A. E. Why Do the Monetary Authorities Smooth Interest Rates? Mimeo, London School of Economics (1996). 
[13] Lucas, Robert E. Jr., Econometric Policy Evaluation: A Critique. Carnegie-Rochester Conference Series on Public Affairs 1 (1976).

[14] McCallum, Bennett T. and Edward Nelson. An Optimizing IS-LM Specification for Monetary Policy and Business Cycle Analysis. NBER Working Paper \#5875 (1997).

[15] Rotemberg, Julio J. and Michael Woodford. An Optimization-Based Econometric Framework for the Evaluation of Monetary Policy. Mimeo (1997).

[16] Rudebusch, Glenn D. Federal Reserve Interest Rate Targeting, Rational Expectations, and the Term Structure. Journal of Monetary Economics 35 (1995), 245-274.

[17] Sack, Brian. Uncertainty, Learning, and Gradual Monetary Policy. Mimeo, Federal Reserve Board (1998).

[18] Sims, Christopher. Macroeconomics and Reality. Econometrica 48 (1980), 1-48.

[19] Sims, Christopher. Are Forecasting Models Usable for Policy Analysis? Federal Reserve Bank of Minneapolis Quarterly Review (1996), 2-16.

[20] Svensson, Lars E.O. Inflation Targeting: Some Extensions. NBER Working Paper \#5962 (1997).

[21] Taylor, John B. Discretion Versus Policy Rules in Practice. Carnegie-Rochester Conference Series on Public Policy 39 (1993), 195-214.

[22] Wieland, Volker. Learning by Doing and the Value of Optimal Experimentation. Finance and Economic Discussion Series 96-5, Federal Reserve Board (1996).

[23] Wieland, Volker. Monetary Policy and Uncertainty about the Natural Rate of Unemployment. Mimeo, Federal Reserve Board (1997). 